DOI: http://dx.doi.org/10.18203/2320-1770.ijrcog20180867

\title{
Transvaginal sonographic evaluation of cervical length in the second trimester as a risk factor for preterm delivery
}

\author{
Shaila Sherafudeen*, Anju Viswanath, Sheena Mary Joseph
}

Department of Obstetrics and Gynecology, Government Medical College, Trivandrum, Kerala, India

Received: 09 December 2017

Accepted: 31 January 2018

\section{*Correspondence:}

Dr. Shaila Sherafudeen,

E-mail: shailas58@gmail.com

Copyright: (c) the author(s), publisher and licensee Medip Academy. This is an open-access article distributed under the terms of the Creative Commons Attribution Non-Commercial License, which permits unrestricted non-commercial use, distribution, and reproduction in any medium, provided the original work is properly cited.

\section{ABSTRACT}

Background: Preterm delivery continues to be a significant obstetric problem in view of prematurity complications that an immature new born develops. Cervical length is considered to be one of the important predictors of the risk of preterm delivery. There are only a few studies evaluating cervical length as risk factor for preterm delivery in the Indian population. The present study is undertaken to estimate the risk of preterm delivery in women with cervical length $<2.5 \mathrm{~cm}$ measured by transvaginal sonography at 18-24 weeks of gestation in South Indian population.

Methods: All booked singleton pregnancies attending the Out Patient Department OPD at SAT Hospital Trivandrum, who have the correct dating and came for anomaly scan between 18-24 weeks were included for cervical length measurement with transvaginal ultrasound scanning. Selected patients were then followed till pregnancy was terminated. The outcome of pregnancy in term of period of gestation at delivery was assessed.

Results: A total of 202 antenatal patients were followed up from 18-24 weeks of gestation till their termination of pregnancy and among these 101 patients had a cervical length $<2.5 \mathrm{~cm}$. The mean cervical length in patients with preterm delivery $(n=63)$ was $2.4 \mathrm{~cm}$ and in term delivery $(n=139)$ was $2.91 \mathrm{~cm}$ respectively. Of the total patients $(n=202)$ followed, 31.2\% $(n=63)$ had preterm delivery whereas $68.8 \%(n=139)$ had term delivery. In the 101 patients with cervical length $<2.5 \mathrm{~cm}, 76.2 \%(\mathrm{n}=48)$ had preterm delivery when compared to $23.8 \%(\mathrm{n}=15)$ of patients with cervical length $>2.5 \mathrm{~cm}(\mathrm{n}=101)$. The cervical length of $<2.5 \mathrm{~cm}$ at $18-24$ weeks of gestation was found to be statistically significant ( $\mathrm{p}$ value-<0.001) in relation to outcome of delivery. The relative risk for preterm delivery in patients with cervical length $<2.5 \mathrm{~cm}$ was 3.2 times that of patients with $>2.5 \mathrm{~cm}$. The history of previous preterm delivery was found to be statistically significant $(p$ value $=<0.001)$ for preterm labour in future pregnancies. The relative risk for preterm delivery in patients with previous history of preterm labour was 3 times when compared to patients with previous term delivery. Patients with history of UTI (urinary tract infection) had 2.3 times risk for preterm delivery and relative risk for preterm delivery in patient with vaginitis was 6.8 times. The cervical length of $<2.5 \mathrm{~cm}$ and vaginitis are independent risk factor for preterm delivery.

Conclusions: Short cervix (cervical length $<2.5 \mathrm{~cm}$ ) at $18-24$ weeks of gestation is a risk factor for preterm delivery. A cervical length $<2.5 \mathrm{~cm}$ has a relative risk of 3 for preterm delivery. Previous history of preterm birth has 3 times increased risk of preterm delivery in future pregnancies. History of urinary tract infection and vaginitis also increases risk of preterm delivery. The cervical length at 18-24 weeks, history of vaginitis and UTI were found to be independent risk factors for preterm delivery.

Keywords: Preterm delivery, Short cervix, Ultrasonography 


\section{INTRODUCTION}

Preterm delivery is a significant obstetric problem in view of prematurity complications that an immature new born develops. Preterm delivery is responsible for nearly $75 \%$ of all neonatal death and neurological complications.

By identifying women with high risk of preterm delivery an attempt can be made to reduce the same. Recently, several studies have been conducted in pregnancies considered to be at high risk, either because of a history of previous mid-trimester miscarriage or early preterm delivery, and those presenting with preterm labor, have reported that cervical assessment can provide useful prediction of preterm delivery. Cervical length is considered to be one of the important predictors of the risk of preterm delivery. In the era of ultrasound imaging transvaginal ultrasound assessment of cervical length is considered to be more accurate. ${ }^{1}$

Studies of transvaginal cervical sonography have reported different thresholds depending on the patients studied (symptoms versus no symptoms) and the goal of the analysis (accurate detection of preterm labor in women with symptoms versus prediction of preterm birth in asymptomatic outpatients). In symptomatic women, the optimal threshold to exclude a diagnosis of preterm labor is $30 \mathrm{~mm} \cdot{ }^{2-7}$ A cervical length of $18-20 \mathrm{~mm}$ has optimal positive predictive value in this setting.

Cervical length is one of the major determinants of preterm delivery. The risk of preterm birth varies inversely with cervical length measured by transvaginal / transabdominal scan at 20-24 weeks. Ultrasound assessment of cervical length has therefore become an important component of obstetric scan.

Several studies have reported that transvaginal cervical length assessment may be a useful tool for prediction of preterm delivery. ${ }^{8-10}$ Many studies have found that cervical length at 20-24 weeks is a reliable predictor of preterm delivery.

\section{METHODS}

The Prospective cohort study was conducted in Sri Avittom Tirunal Hospital, Medical College
Trivandrum.A total of 202 Booked antenatal cases were included in this study.

\section{Inclusion criteria}

All singleton pregnancies who have the correct dating (reliable LMP in the background of regular menstrual cycles or ultrasound dating done in the first trimester), who came for anomaly scan between 18-24 weeks were included for cervical length measurement with ultrasound scanning done from February $1^{\text {st }} 2016$ to July $15^{\text {th }} 2016$.

\section{Exclusion criteria}

Those who developed medical or surgical complications in the later period and got terminated iatrogenically, those who missed follow up, multiple pregnancies and pregnancy with fetal anomalies.

\section{Statistical analysis}

The statistical significance is calculated by chi square test and paired ANOVA test wherever applicable. Ethical clearance was obtained from the Human Ethics Committee, Government Medical College.

\section{RESULTS}

Out of the total patients studied, $40.6 \%(n=82)$ belonged to the age group of $25-29$ years and $37.1 \% \quad(n=75)$ belonged to age group of 20-24 years. $49.5 \%(n=100)$ of patients included primigravidas and rest $50.5 \%(\mathrm{n}=102)$ were multigravidas. Out of the 102 multigravidas studied, $70.6 \%(\mathrm{n}=72)$ patients had previous history of preterm delivery and $29.4 \%(n=30)$ had term deliveries. $75.5 \%$ $(n=77)$ of the multigravidas $(n=102)$ had previous vaginal delivery and rest $24.5 \%(n=25)$ had caesarean section. Of the total 202 antenatal patients who were followed, $31.2 \%(n=63)$ had preterm delivery and $68.8 \%(n=139)$ had term delivery.

Among the 202 patients studied, 46.2\% (n=6) of the patients $<20$ years had preterm delivery and $53.8 \%(n=7)$ had term deliveries. Among the age groups, 20-24 years, 25-39 years and 30-34 years, the percentages of preterm deliveries were $28 \%(n=21), 39 \%(n=32)$ and $10.5 \%$ $(\mathrm{n}=2)$ respectively.

Table 1: Percentages of term and preterm deliveries in relation to gestational age of previous deliveries.

\begin{tabular}{|c|c|c|c|c|c|c|c|c|c|}
\hline \multirow[b]{3}{*}{ GA of previous delivery } & \multicolumn{4}{|c|}{ Category } & \multicolumn{2}{|c|}{ Total } & \multirow[t]{2}{*}{$\chi^{2}$} & \multirow[t]{2}{*}{ df } & \multirow[t]{2}{*}{$\mathbf{P}$} \\
\hline & Pre & erm & Ter & & & & & & \\
\hline & $\mathrm{N}$ & $\%$ & $\mathrm{~N}$ & $\%$ & $\mathrm{~N}$ & $\%$ & & & \\
\hline Preterm & 18 & 60 & 12 & 40 & 30 & 100 & 16.177 & 1 & $<0.001$ \\
\hline Term & 14 & 19.4 & 58 & 80.6 & 72 & 100 & & & \\
\hline Total & 32 & 31.4 & 70 & 68.6 & 102 & 100 & & & \\
\hline
\end{tabular}


Table 2: Mean cervical length in patients with term and preterm deliveries.

\begin{tabular}{|c|c|c|c|c|c|}
\hline \multirow{2}{*}{$\begin{array}{l}\text { Outcome } \\
\text { delivery }\end{array}$} & \multirow[t]{2}{*}{$\mathbf{N}$} & \multicolumn{2}{|c|}{ CX length in } & \multirow[t]{2}{*}{$\mathbf{t}$} & \multirow[t]{2}{*}{ p } \\
\hline & & Mean & Sd & & \\
\hline Preterm & 63 & 2.40 & 0.38 & \multirow{2}{*}{6.489} & \multirow{2}{*}{$<0.001$} \\
\hline Term & 139 & 2.91 & 0.48 & & \\
\hline
\end{tabular}

Among all primigravidas $(\mathrm{n}=100), 31 \% \quad(\mathrm{n}=31)$ had preterm deliveries and 69\% $(n=69)$ had term deliveries. The obstetric score of the patients were not statistically significant with the outcome of delivery ( $p$ value $=0.472$ ). Of the total 102 multigravidas, $32.5 \%(n=25)$ of patients with previous vaginal delivery $(n=77)$ had preterm labour, whereas $28 \%(n=7)$ of previous caesarean section had preterm delivery.

Table 3: Percentages of patients with UTI having term and preterm deliveries.

\begin{tabular}{|c|c|c|c|c|c|c|c|c|c|}
\hline & $\mathrm{Ca}$ & & & & Tota & & $\chi^{2}$ & df & $\mathbf{P}$ \\
\hline & Pr & & Ter & & & & & & \\
\hline UTI & $\mathrm{N}$ & $\%$ & $\mathrm{~N}$ & $\%$ & $\mathrm{~N}$ & $\%$ & & & \\
\hline Present & 51 & 39.2 & 79 & 60.8 & 130 & 100 & 10.993 & 1 & 0.001 \\
\hline No & 12 & 16.7 & 60 & 83.3 & 72 & 100 & & & \\
\hline Total & 63 & 31.2 & 139 & 68.8 & 202 & 100 & & & \\
\hline Relative Risk (95\% CI for RR) & & $4(1.3$ & -4.1 & & & & & & \\
\hline
\end{tabular}

Table 4: Percentages of term and preterm deliveries in patients with history of vaginitis.

\begin{tabular}{|c|c|c|c|c|c|c|c|c|c|}
\hline & \multicolumn{4}{|c|}{ Category } & \multicolumn{2}{|c|}{ Total } & \multirow[t]{2}{*}{$\chi^{2}$} & \multirow[t]{2}{*}{ df } & \multirow[t]{2}{*}{ p } \\
\hline & Pr & & Terı & & & & & & \\
\hline Vaginitis & $\mathrm{N}$ & $\%$ & $\mathrm{~N}$ & $\%$ & $\mathrm{~N}$ & $\%$ & & & \\
\hline Present & 53 & 60.2 & 35 & 39.8 & 88 & 100 & 61.27 & 1 & $<0.001$ \\
\hline No & 10 & 8.8 & 104 & 91.2 & 114 & 100 & & & \\
\hline Total & 63 & 31.2 & 139 & 68.8 & 202 & 100 & & & \\
\hline Relative Risk (95\% CI for RR) & 6.8 & $709-12$ & & & & & & & \\
\hline
\end{tabular}

Table 5: Percentages of term and preterm delivery in patients with cervical length $<2.5 \mathrm{~cm}$ and $>2.5 \mathrm{~cm}$.

\begin{tabular}{|c|c|c|c|c|c|c|c|c|c|}
\hline \multirow{3}{*}{ Cervical length in $\mathrm{cm}$} & \multicolumn{4}{|c|}{ Category } & \multicolumn{2}{|c|}{ Total } & \multirow[t]{2}{*}{$\chi^{2}$} & \multirow[t]{2}{*}{ df } & \multirow[t]{2}{*}{ p } \\
\hline & Pre & & Terı & & & & & & \\
\hline & $\mathrm{N}$ & $\%$ & $\mathrm{~N}$ & $\%$ & $\mathrm{~N}$ & $\%$ & & & \\
\hline$<2.5$ & 48 & 76.2 & 53 & 38.1 & 101 & 50.0 & 25.120 & 1 & $<0.001$ \\
\hline$>2.5$ & 15 & 23.8 & 86 & 61.9 & 101 & 50.0 & & & \\
\hline Total & 63 & 100.0 & 139 & 100.0 & 202 & 100.0 & & & \\
\hline
\end{tabular}

Table 6: Distribution of preterm labour based on period of gestation.

\begin{tabular}{|lllll|}
\hline $\begin{array}{l}\text { GA at } \\
\text { delivery } \\
\text { in weeks }\end{array}$ & $\begin{array}{l}\text { Cervical } \\
\text { length in } \mathbf{c m}\end{array}$ & Total & $\begin{array}{l}\text { RR of preterm } \\
\text { labour in }<2.5\end{array}$ & $\mathbf{> 2 . 5}$ \\
\hline$<32$ & 12 & 3 & 15 & $4.0(1.16-13.5$ \\
\hline $32-34$ & 16 & 3 & 19 & $4.67(2.02-10.78)$ \\
\hline $34-36$ & 20 & 9 & 29 & $3.20(1.92-5.33)$ \\
\hline Total & 48 & 18 & & \\
\hline
\end{tabular}

The mode of previous delivery was not statistically significant ( $p$ value $=0.0676$ ) in relation the outcome of present pregnancy.
Of the total 102 multigravidas, $60 \%(n=18)$ of patients with previous preterm delivery $(\mathrm{n}=30)$ had preterm labour in the present pregnancy, whereas only $19.4 \%(n=14)$ of patients with previous term delivery $(n=72)$ had preterm labour.

The history of previous preterm delivery was found to be statistically significant $(\mathrm{p}$ value $=<0.001)$ for preterm labour in future pregnancies.

The relative risk for preterm delivery in patients with previous history of preterm labour was 3 times when compared to patients with previous term delivery. 
Table 7: Percentages of term and preterm delivery in patients with cervical funneling.

\begin{tabular}{|c|c|c|c|c|c|c|c|c|c|}
\hline & \multicolumn{4}{|c|}{ Category } & \multicolumn{2}{|c|}{ Total } & \multirow[t]{2}{*}{$\chi^{2}$} & \multirow[t]{2}{*}{ df } & \multirow[t]{2}{*}{ p } \\
\hline & Pre & & Teri & & & & & & \\
\hline Funelling & $\mathrm{N}$ & $\%$ & $\mathrm{~N}$ & $\%$ & $\mathrm{~N}$ & $\%$ & & & \\
\hline Yes & 10 & 76.9 & 3 & 23.1 & 13 & 100 & 13.542 & 1 & $<0.001$ \\
\hline No & 53 & 28 & 136 & 72 & 189 & 100 & & & \\
\hline Total & 63 & 31.2 & 139 & 68.8 & 202 & 100 & & & \\
\hline Relative Risk (95\% CI for RR) & \multicolumn{9}{|c|}{$2.743(1.885-3.992)$} \\
\hline
\end{tabular}

Table 8: Binary logistic regression model for preterm labour.

\begin{tabular}{|llllllllll} 
& B & S.E. & Wald & df & p & OR & \multicolumn{2}{c|}{ L5 C. I. for OR } \\
\hline Cervical length & 1.682 & 0.508 & 10.957 & 1 & 0.001 & 5.38 & 1.99 & 14.56 \\
\hline Vaginitis & 2.301 & 0.421 & 29.95 & 1 & $<0.001$ & 9.99 & 4.38 & 22.78 \\
\hline Funelling & 0.739 & 0.764 & 0.935 & 1 & 0.334 & 2.09 & 0.47 & 9.36 \\
\hline UTI & 0.589 & 0.456 & 1.669 & 1 & 0.196 & 1.80 & 0.74 & 4.41 \\
\hline Constant & -5.561 & 1.335 & 17.356 & 1 & $<0.001$ & 0.004 & & \\
\hline
\end{tabular}

\section{DISCUSSION}

In this study, a total of 202 antenatal women were followed up from 18-24 weeks of gestation till their termination of pregnancy. Out of which 101 patients had a cervical length $<2.5 \mathrm{~cm}$ and another 101 patients with a length $>2.5 \mathrm{~cm}$. Of the total patients $(\mathrm{n}=202)$ followed, $31.2 \%(\mathrm{n}=63)$ had preterm delivery whereas $68.8 \%$ $(n=139)$ had term delivery. The mean cervical length in patients with preterm delivery $(\mathrm{n}=63)$ was $2.4 \mathrm{~cm}$ and in term delivery $(n=139)$ was $2.91 \mathrm{~cm}$ respectively, which was less than that in another large study. ${ }^{11}$

In the 101 patients with cervical length $<2.5 \mathrm{~cm}, 76.2 \%$ $(n=48)$ had preterm delivery when compared to $23.8 \%$ $(n=15)$ of patients with cervical length $>2.5 \mathrm{~cm}(\mathrm{n}=101)$.

The cervical length of $<2.5 \mathrm{~cm}$ at $18-24$ weeks of gestation was found to be statistically significant ( $p$ value-<0.001) in relation to outcome of delivery, similar to other major studies. ${ }^{12}$ The relative risk for preterm delivery in patients with cervical length $<2.5 \mathrm{~cm}$ was 3.2 times that of patients with $>2.5 \mathrm{~cm}$.

The relative risk for preterm delivery in patients with cervical length $<2.5 \mathrm{~cm}(\mathrm{n}=101)$ before 32 weeks and between 32- 34 weeks of gestation was similarly 4 times when compared to patients with cervical length $>2.5 \mathrm{~cm}$. These findings were different from that found in another study. ${ }^{13}$

In the 13 patients who had cervical funneling, $76.9 \%$ $(\mathrm{n}=10)$ had preterm delivery and cervical funneling was statistically significant ( $\mathrm{p}$ value $=<0.001$ ).

Majority of patients $(40.6 \%)$ in this study group belonged to $25-29$ years of age, followed by $37.1 \%$ of patients in
20-24 years of age. Among the age groups, 20-24 years, 25-39 years and 30-34 years, the percentages of preterm deliveries were $28 \%(\mathrm{n}=21), 39 \% \quad(\mathrm{n}=32)$ and $10.5 \%$ $(n=2)$ respectively.

In this study, $50.5 \%(\mathrm{n}=102)$ of antenatal women studied $(n=202)$ were multigravidas and $49.5 \% \quad(n=100)$ were primigravidas. $70.6 \% \quad(n=72)$ of the multigravidas $(n=102)$ had previous history of preterm delivery and among them $75.5 \%(n=77)$ had previous vaginal delivery and rest $24.5 \%(n=25)$ had caesarean section. Among all primigravidas $(\mathrm{n}=100), 31 \% \quad(\mathrm{n}=31)$ had preterm deliveries and $69 \% \quad(n=69)$ had term deliveries. The obstetric score of the patients was not found to be statistically significant with the outcome of delivery(p value $=0.472)$ in this study. $32.5 \% \quad(n=25)$ of multigravidas $(\mathrm{n}=102)$ with previous vaginal delivery $(n=77)$ had preterm labour, whereas $28 \% \quad(n=7)$ of previous caesarian section had preterm delivery. The mode of previous delivery was not statistically significant ( $\mathrm{p}$ value $=0.0676$ ) in relation the outcome of present pregnancy.

In this study, $60 \%(n=18)$ of patients with previous preterm delivery $(n=30)$ had preterm labour in the present pregnancy. The history of previous preterm delivery was found to be statistically significant $(p$ value $=<0.001$ ) for preterm labour in future pregnancies in this study similar to other studies. ${ }^{14-19}$

The relative risk for preterm delivery in patients with previous history of preterm labour was 3 times when compared to patients with previous term delivery.

In the 102 multigravidas, $34.8 \%(n=16)$ of patients with history of previous abortion $(n=46)$ had preterm delivery, when compared to $28.6 \% \quad(n=16)$ of patients without history of abortion $(n=56)$. History of previous abortion 
was not found to be statistically significant ( $p$ value $=0.501$ ) for future preterm delivery. Similarly, history of previous ectopic gestation was also statistically insignificant $(p$ value $=0.500)$ in determining outcome of present pregnancy.

$37.1 \%(n=13)$ of multigravidas $(n=102)$ with previous history of dilatation and curettage had preterm delivery and was found to be statistically insignificant ( $p$ value $=0.403$ ) for preterm delivery.

Of the various co-morbidities studied in this study group, history of hypertension ( $p$ value $=0.9340$, diabetes ( $p$ value $=0.976)$, thyroid disease $(p$ value $=0.705)$ were all statistically insignificant in determining outcome of delivery.

Of the 202 antenatal studied, 39.2\% $(n=20)$ of patients with an Hb-10-10.9 g/dl $(\mathrm{n}=51)$ had preterm delivery, whereas $29.1 \%(n=41)$ of patients with $\mathrm{Hb}>11 \mathrm{~g} / \mathrm{dl}$ had preterm labour. The hemoglobin status of patient is statistically insignificant ( $\mathrm{p}$ value $=0.240$ ) with relation to outcome of delivery. The blood group of the patient was statistically insignificant $(p$ value $=0.240)$ in relation to outcome of delivery.

Of the total studied patients, 39.2\% $(n=51)$ of patients with urinary tract infection $(n=130)$ had preterm delivery, and $60.8 \%(n=79)$ had term delivery. The previous history of UTI was statistically significant ( $p$ value $=0.001$ ) in determining outcome of delivery. Patients with history of UTI had 2.3 times risk for preterm delivery when compared to rest of the cohort.

In the total patients with history of vaginitis $(n=88)$, $60.2 \% \quad(n=53)$ had preterm delivery with a $p$ value of $<0.001$, which was statistically significant. The relative risk for preterm delivery in patient with vaginitis was 6.8 times.

Binary logistic regression model for Preterm labour, shows that cervical length of $<2.5 \mathrm{~cm}$ and vaginitis are independent risk factor for preterm delivery.

\section{CONCLUSION}

Short cervix (cervical length $<2.5 \mathrm{~cm}$ ) at $18-24$ weeks of gestation is a risk factor for preterm delivery. A cervical length $<2.5 \mathrm{~cm}$ at $18-24$ weeks of gestation has a relative risk of 3 for preterm delivery. Previous history of preterm birth has 3 times increased risk of preterm delivery in future pregnancies. History of urinary tract infection and vaginitis also increases risk of preterm delivery. The cervical length of $<2.5 \mathrm{~cm}$ at $18-24$ weeks of gestation, history of vaginitis and UTI were found to be independent risk factors for preterm delivery.

Funding: No funding sources

Conflict of interest: None declared
Ethical approval: The study was approved by the Institutional Ethics Committee

\section{REFERENCES}

1. Iams JD, Johnson FF, Sonck J, Sachs L, Gebauer C, Samuels P. Cervical competence as a continuum: a study of ultrasonographic cervical length and obstetric performance. Am J Obset Gynecol. 1995; 172:1097-1106.

2. Murakawa H, Utumi T, Hasagawal I, Tanaka K, Fuzimori R. Evaluation of thereatened preterm delivery by transvaginal ultrasonographic measurement of cervical length. Obstet Gynecol. 1993;82:829-32.

3. Iams JD, Paraskos J, Landon MB, Teteris JN, Johnson FF. Cervical sonography in preterm labor. Obstet Gynecol. 1994;84:40-6.

4. Gomez R, Galasso M, Romero R, Mazor M, SorokinY, Goncalves L, et al. Ultrasonographic examination of the uterine cervix is better than cervical digital examinations a predictor of the likelihood of preterm delivery in patients with preterm labor and intact membranes. Am J Obstet Gynecol. 1994;171:956-64.

5. Timor-Tritsch I, Boozarjomehri F, Masakowski Y, Monteagudo A, Chao CR. Can a snapshot sagittal view of the cervix by transvaginal ultrasonography predict active preterm labor? Am J Obstet Gynecol. 1996;174:990-5.

6. Crane JMG, Van den Hof F, Armson BA, Liston R. Transvaginal ultrasound in the prediction of preterm delivery: Singleton and twin gestation. Obstet Gynecol. 1997;90:357-63.

7. Leitich H, Brumbauer M, Kaider A, Egarter C, Husslein P. Cervical length and dilation of the internal os detected by vaginal ultrasonography as markers for preterm delivery: A systematic review. Am J Obstet Gynecol. 1999;181:1465-72.

8. Bergella V. The short and funneled cervix:what do I do now? Contemp Ob/Gyn. 2004;49:26-34.

9. American College of Radiology. ACR Appropriateness Criteria: Expert Panel on Women's Imaging. Premature cervical dilatation. American College of Radiology, Reston Va 1999. Available at http://www.acr.org

10. American college of Obstetricians and Gynecologists Committee on Quality Assessment. Criteria Set. 18. October 1996

11. Heath VC, Southall TR, Souka AP, Elisseou A, Nicolaides KH. Cervical length at 23 weeks of gestation: prediction of spontaneous preterm delivery. Ultrasound Obstet Gynecol. 1998 Nov 1;12(5):312-7.

12. Berghella V, Tolosa JE, Kuhlman K, Weiner S, Bolognese RJ, Wapner RJ. Cervical ultrasonography compared with manual examination as a predictor of preterm delivery. Am J Obstet Gynecol. 1997;177:723-30. 
13. Heath VC, Southall TR, Souka AP, Elisseou A, Nicolaides KH. Cervical length at 23 weeks of gestation: prediction of spontaneous preterm delivery. Ultrasound Obstet Gynecol. 1998;12:312-7.

14. To MS, Alfirevic Z, Heath VC, Cicero S, Cacho AM, Williamson PR, et al. Cervical cerclage for prevention of preterm delivery in women with short cervix: randomised controlled trial. Lancet. 2004;363:1849-53.

15. Owen J, Yost N, Berghella V, Thom E, Swain M, Dildy GA III, et al. Mid-trimester endovaginal sonography in women at high risk for spontaneous preterm birth. JAMA. 2001;286:1340-8.

16. Crane JM, Hutchens D. Use of transvaginal ultrasonography to predict preterm birth in women with a history of preterm birth. Ultrasound Obstet Gynecol. 2008;32:640-5.

17. To MS, Palaniappan V, Skentou C, Gibb D, Nicolaides KH. Elective cerclage vs. ultrasound- indicated cerclage in high-risk pregnancies. Ultrasound Obstet Gynecol. 2002;19:475-7.

18. Andrews WW, Copper R, Hauth JC, Goldenberg RL, Neely C, Dubard M. Second-trimester cervical ultrasound: associations with increased risk for recurrent early spontaneous delivery. Obstet Gynecol. 2000;95:222-6.

19. Durnwald CP, Walker H, Lundy JC, Iams JD. Rates of recurrent preterm birth by obstetrical history and cervical length. Am J Obstet Gynecol. 2005;193:1170-4.

Cite this article as: Sherafudeen $\mathrm{S}$, Viswanath A, Joseph SM. Transvaginal sonographic evaluation of cervical length in the second trimester as a risk factor for preterm delivery. Int J Reprod Contracept Obstet Gynecol 2018;7:921-6. 